\title{
HIDROGEOQUÍMICA DE SÃO JOSÉ DOS CAMPOS, JACAREÍ E CAÇAPAVA, NO VALE DO PARAÍBA DO SUL
}

Emanuel L’Apiccirella1 ${ }^{1}$ Mateus Simonato²; Alexsandra Leitão ${ }^{3}$; Daniel Brandão ${ }^{4}$; José Eduardo Campos ${ }^{5}$.

Resumo - A região sudoeste do vale do rio Paraíba do Sul, na Bacia de Taubaté tem uma elevada dependência de água subterrânea, fazendo necessária a melhor compreensão dessas águas para a sua gestão. São águas de dois ambientes hidrogeológicos distintos: o aquífero Cristalino e o Sistema Aquífero Taubaté. Neste trabalho foram caracterizadas e classificadas quatro zonas hidroquímicas: Taubaté1, Bicarbonatadas sódicas; Taubaté2, Bicarbonatadas potássicas; Taubaté3, Bicarbonatadas sódicas a Bicarbonatadas cálcicas; e Cristalino, Bicarbonatadas sódicas a Bicarbonatadas cálcicas. Esta caracterização permitiu observar uma interação de águas do aquífero fraturado Cristalino com águas dos aquíferos granulares do SAT. Foram verificadas ocorrências anômalas de nitrato e cloreto nas águas, decorrentes de interferência antrópica, que embora tenham sido pontuais e abaixo dos limites de referência aplicáveis, alertam para a necessidade de melhorias na gestão dos aquíferos.

\begin{abstract}
The southwest portion of the Paraíba River Valley along the cities of Jacarei, São José dos Campos and Caçapava in Taubaté Basin has a high-level dependence on groundwater resources, bringing the need to improve the knowledge for a better water resources management. Groundwater is there in two distinct hydrogeological environments: the Cristalino Aquifer and the Taubaté Aquifer System. Four distinct hydrochemical zones of water were characterized and classified: Taubaté1, sodic bicarbonate; Taubaté2, bicarbonate potassic; Taubaté3, bicarbonate sodic to calcic bicarbonate; and Cristalino, bicarbonate sodic to calcic bicarbonate. This characterization revealed that there is an interaction between waters from the fractured Cristalino Aquifer and the granular Taubaté Aquifer System. Nitrate and Chloride anomalous occurrences were found due to anthropic interference. Although they occurred as punctual events and at levels below the applicable guidelines, it must serve as a warning about the need for improvements in local water managements.
\end{abstract}

Palavras-Chave - hidrogeoquímica; recursos hídricos; Vale do Paraíba.

\footnotetext{
${ }^{1}$ Hidrogeólogo da Biotita Hidrogeologia e Meio Ambiente Ltda. Rua Paulo Orozimbo, 1100, Aclimação - São Paulo - SP - CEP $01535-001$. Fone:11 98886-5005. Email: emanuel.lapiccirella@biotita.com.br

${ }^{2}$ Hidrogeólogo da SIGA Serviços de Investigações Geotécnicas e Ambientais Ltda. Av. Treze de Maio, 462, São Bernardo do Campo-SP, CEP 09812-570. Cel. 11 99266-9331. Email: msimonato@ sigageo.com.br

${ }^{3}$ Geóloga da RHiGeMA - Recursos Hídricos, Geologia e Meio Ambiente, Rua Benedito Hilarião de Souza, 80. Ilhabela - SP. CEP: 11630-000. Fone: 12 3862-2461 Email: alexsandra.leitao@rhigema.com.br

${ }^{4}$ Geólogo da RHiGeMA - Recursos Hídricos, Geologia e Meio Ambiente, Rua Benedito Hilarião de Souza, 80. Ilhabela - SP. CEP: 11630-000.

Fone: 11 98238-3083. Email: daniel.brandao@rhigema.com.br

${ }^{5}$ Geólogo do Departamento de Águas e Energia Elétrica - Rua Boa Vista, 175, Centro - São Paulo - SP - CEP 01014-000. Fone: 11 3293-3742.

Email: jose.campos@ daee.sp.gov.br
} 


\section{1 - INTRODUÇÃO}

Este trabalho apresenta uma avaliação hidroquímica das águas subterrâneas do aquífero fraturado Cristalino e dos aquíferos granulares que compõem o Sistema Aquífero Taubaté - SAT, nos municípios de Jacareí, São José dos Campos e Caçapava; bem como responde sobre a interação de águas entre estes aquíferos; e avalia o impacto de influências antrópicas na qualidade dessas águas. É um trabalho decorrente da execução de um diagnóstico hidrogeológico, realizado em 2014 e 2015 pela empresa C3 Planejamento Consultoria e Projeto Ltda. para o Departamento de Águas e Energia Elétrica - DAEE.

A área de estudo, Figura 1, está situada na região do Vale do Paraíba no Estado de São Paulo, na Unidade de Gerenciamento de Recursos Hídricos - UGRHI 2 - Paraíba do Sul, abrange a totalidade dos territórios dos municípios de Jacareí, São José dos Campos e Caçapava, com uma extensão total de $1.938 \mathrm{~km}^{2}$ e população total de 925.887 habitantes (IBGE, 2010), sendo que 97\% são residentes de áreas urbanas. A principal via de acesso é a Rodovia Presidente Dutra - BR-116.

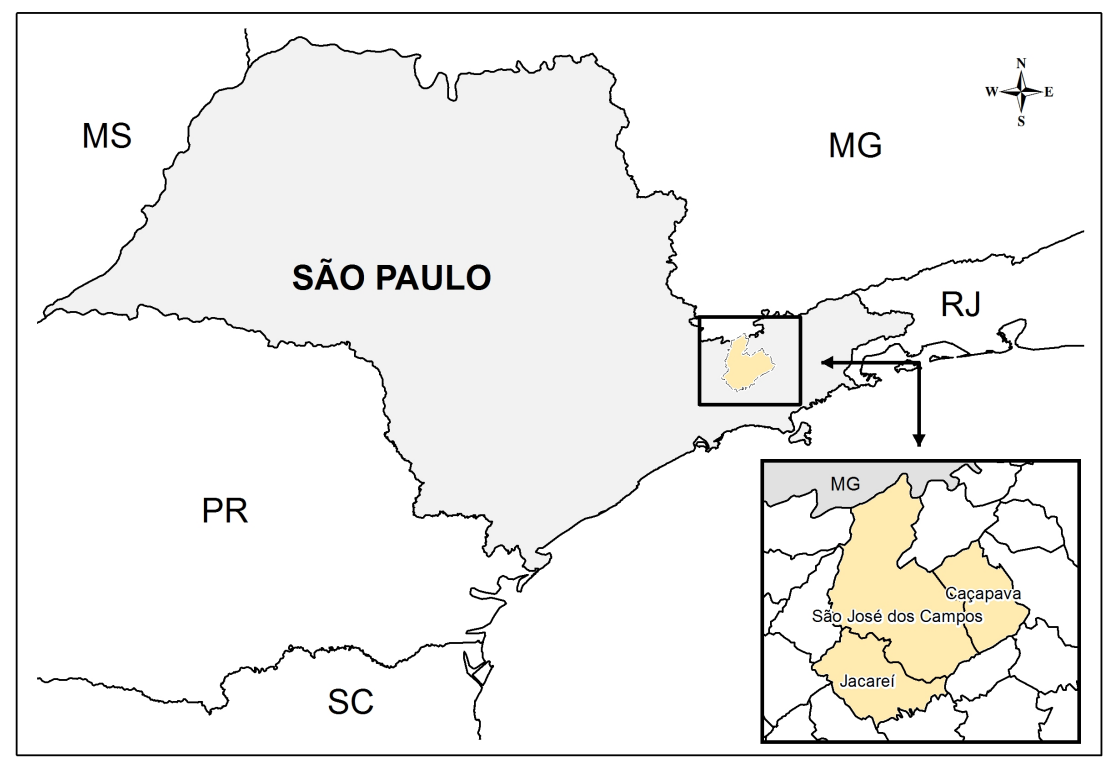

Figura 1. Localização da área de estudo.

Conforme Custódio e Llamas (1983), a identificação e quantificação das propriedades e constituintes das águas subterrâneas permite verificar processos dinâmicos dos fluxos subterrâneos e influências antrópicas na qualidade das águas, subsidiando a gestão e a proteção dos recursos hídricos. Um estudo hidrogeoquímico permite explicar a composição química; predizer mudanças nessa composição; e determinar o grau de proteção da quantidade e qualidade da água subterrânea. 
Nos últimos anos foram desenvolvidos diversos estudos hidrogeológicos na Bacia de Taubaté (Hirata, 1994; Iritani, 1999; Vidal e Chang, 2002, 2004; Vidal et al, 2004) que se destacam pelas significativas contribuições à caracterização geológica da região, com diferentes escalas de abordagens e foram a base de conhecimento para o desenvolvimento do presente estudo.

Este trabalho utiliza dados de 46 amostras de águas subterrâneas, cuja coleta foi realizada em agosto de 2015, em poços tubulares profundos, de abastecimento público, priorizando a maior distribuição espacial possível e com abrangência aos aquíferos da área de interesse, sendo 31 amostras do SAT, 07 de poços mistos, 05 do aquífero Cristalino e 03 indefinidos.

\section{2 - GEOLOGIA E HIDROGEOLOGIA}

$\mathrm{Na}$ área de estudo afloram rochas do embasamento Cristalino, o Grupo Taubaté - Formação Resende e Formação Tremembé-, a Formação Pindamonhangaba e os Depósitos Aluvionares que ocupam as áreas topograficamente mais baixas contornando as drenagens e na planície do Rio Paraíba do Sul. A Figura 2 mostra um bloco diagrama com a geologia local a sul do rio Paraíba do Sul, construído a partir de um mapa geológico elaborado com a superposição de cartografias de trabalhos anteriores, (Riccomini,1989, na escala 1:250.000; e Mancini, 1995, na escala 1:100.000; sobrepostos à base geológica regional CPRM, 2010, na escala 1:750.000).

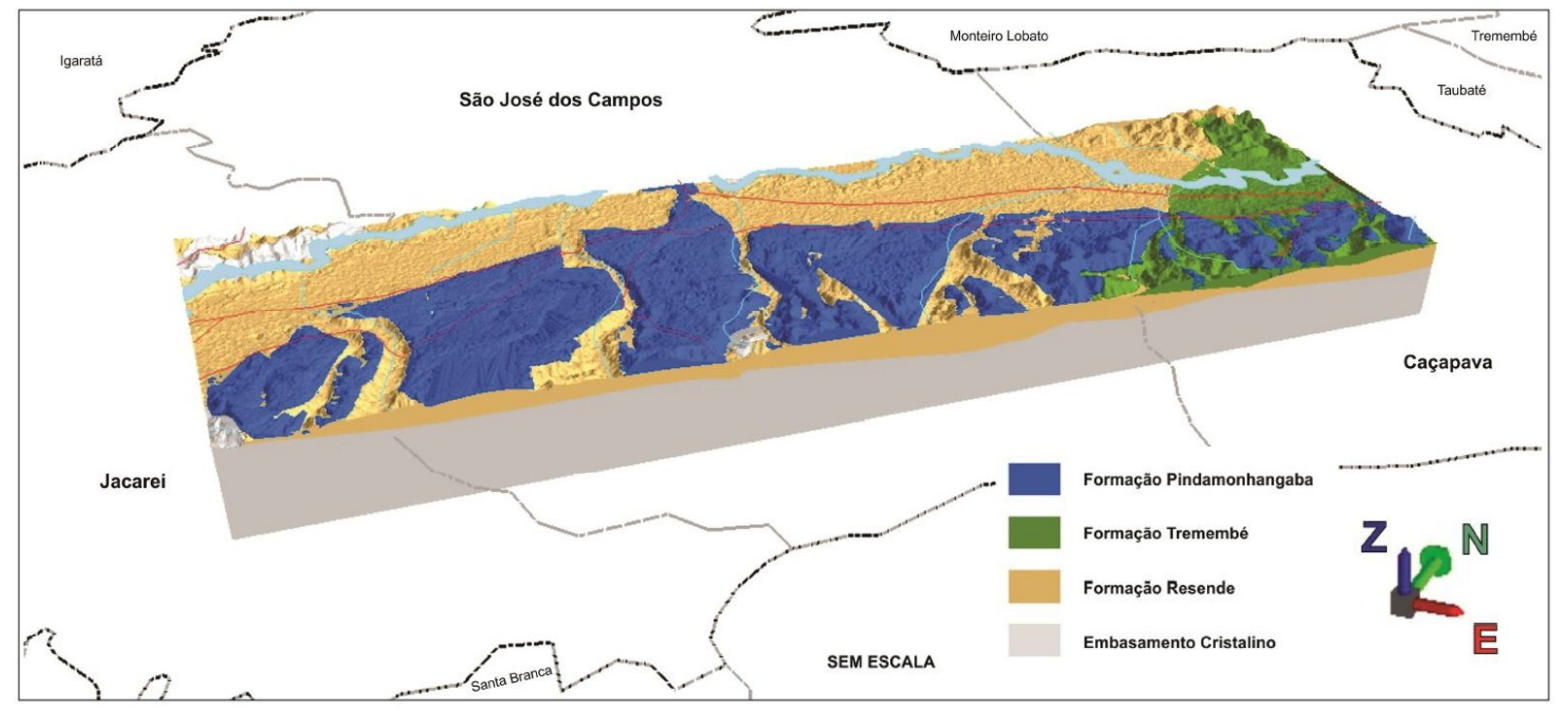

Figura 2. Bloco Diagrama com a Geologia Local.

A segmentação geológica pode ser resumida em três grandes unidades, sendo: os terrenos cristalinos ígneo-metamórficos, de idades desde o Arqueano até o Cenozóico e que constituem o 
embasamento da sequência sedimentar tércio-quaternária; a sequência sedimentar fluvio-lacustrina Terciária, pertencente à Bacia de Taubaté; e os terrenos sedimentares quaternários, predominantemente aluvionares ligados à planície do Rio Paraíba do Sul e seus tributários, e secundariamente depósitos coluvionares.

A água subterrânea ocorre em dois ambientes hidrogeológicos distintos; são eles: o aquífero fraturado do Embasamento Cristalino e os aquíferos granulares dos sedimentos Tércio-Quaternários, de origem fluvial e lacustre, da Bacia de Taubaté. Esses compartimentos hidrogeológicos são aqui denominados, respectivamente, de aquífero Cristalino e Sistema Aquífero Taubaté - SAT.

A área de estudo possui dois importantes altos estruturais: o alto do rio Putins e o alto de Caçapava - descritos em diversos trabalhos (DAEE, 1977; Marques, 1990; Fernandes, 1993; Fernandes e Chang, 2003; Carvalho et al. 2011) - que certamente controlam o fluxo de água subterrânea na interação entre o aquífero do embasamento Cristalino e o SAT.

A Bacia de Taubaté é caracterizada pelo elevado potencial de exploração, principalmente em São José dos Campos, e pela elevada heterogeneidade de seus aquíferos (Campos, 1993).

\section{3 - MATERIAIS E MÉTODOS}

Inicialmente, foram levantados e estudados dados analíticos em estudos anteriores (DAEE, 1977; SABESP, 1990; Vidal, 1997; Vidal e Chang, 2002; CETESB, 2013), auxiliando no entendimento da hidroquímica da área e apoiando a definição de uma rede de amostragem. De modo geral, os poços selecionados para amostragem estavam em funcionamento no momento da coleta. Nos casos em que os poços estavam desligados, procedeu-se com o bombeamento para promover a renovação da agua do interior do poço. Todos os poços selecionados são operados diariamente, garantindo a representatividade das amostras em relação à qualidade do aquífero. Os pontos de coleta foram os mais próximos aos poços e anteriores aos processos de fluoração, cloração, armazenamento e distribuição. Durante a amostragem foram determinados in situ os parâmetros físico químicos: $\mathrm{pH}$, temperatura e condutividade elétrica, com um equipamento multiparâmetro, sendo aguardada a estabilização dos respectivos valores para a realização da amostragem.

As águas coletadas foram filtradas com filtro $0,45 \mu \mathrm{m}$ e analisadas pelo Laboratório de Hidrogeologia e Hidrogeoquímica - H2L do Instituto de Geociências e Ciências Exatas da UNESP. Os métodos e os procedimentos empregado nas análises.

Os parâmetros analisados nas amostras coletadas são apresentados na Tabela $\mathbf{1}$. 
Tabela 1. Parâmetros analisados nas amostras coletadas.

\begin{tabular}{l}
\hline \multicolumn{1}{c}{ Parâmetro Analítico } \\
\hline Alumínio, Bário, Berílio, Cálcio, Cádmio, Cobalto, Crômio, Cobre, Ferro, \\
Magnésio, Manganês, Molibdênio, Níquel, Fósforo, Chumbo, Silício, Estanho, \\
Estrôncio, Vanádio, Zinco. \\
\hline Fluoreto, Cloreto, Nitrito, Nitrato, Fosfato, Sulfato, Brometo \\
\hline $\mathrm{pH}\left(\mathrm{a} 25^{\circ} \mathrm{C}\right)$ \\
\hline Alcalinidade \\
\hline Dureza \\
\hline Cor \\
\hline Turbidez \\
\hline Condutividade \\
\hline
\end{tabular}

Os procedimentos de preservação e respectivas metodologias analíticas são apresentados na Tabela 2.

Tabela 2. Procedimentos de preservação e respectivas metodologias analíticas.

\begin{tabular}{l|l|l|l}
\hline \multicolumn{1}{c|}{ Parâmetro } & \multicolumn{1}{c|}{ Preservação } & \multicolumn{1}{c}{ Técnica } & \multicolumn{1}{c}{ Metodologia } \\
\hline Nitrogênio total & Resfriamento & Quimiofluorescência & $\begin{array}{l}\text { Tekmar 14-900N-074 } \\
\text { Rev.B }\end{array}$ \\
\hline Nitrogênio orgânico & $\mathrm{H}_{2} \mathrm{SO}_{4}$ & $\begin{array}{l}\text { Digestão/Eletrodo } \\
\text { seletivo }\end{array}$ & $\begin{array}{l}\text { SMWWE 21thed-4500 } \\
\text { Norg B }\end{array}$ \\
\hline Nitrogênio amoniacal & $\mathrm{H}_{2} \mathrm{SO}_{4}$ & Eletrodo seletivo & $\begin{array}{l}\text { SMWWE 21th ed-4500 } \\
\text { NH3 B e G }\end{array}$ \\
\hline Nitrato e Nitrito & $\mathrm{H}_{2} \mathrm{SO}_{4}$ & Cromatografia iônica & EPA 300.1 R. 1 \\
\hline Cátions & $\mathrm{HNO}_{3}$ & ICP & SMWW 21 Ed 3120 B \\
\hline Ânions & $\mathrm{Resfriamento}^{\text {Carbono Orgânico }}$ & Cromatografia iônica & EPA 300.1 R. 1 \\
\hline Dissolvido & $\mathrm{H}_{3} \mathrm{PO}_{4} 5 \%$ & $\begin{array}{l}\text { Análise de Ctotal -alta } \\
\text { temperatura }\end{array}$ & EPA 415.1 \\
\hline
\end{tabular}

A validação dos resultados analíticos produzidos pelo laboratório, foi realizada calculando-se o balanço iônico de todas as amostras através da equação definida por Logan (1965), como:

$$
\text { Erro \% = } \left.\left.\left.100 \times\left[\sum \text { (cátions) }\right)-\sum(\text { ânions })\right] /\left[\sum \text { (cátions) }\right)+\sum \text { (ânions }\right)\right]
$$

Os resultados analíticos devem obter resultados nos quais a concentração total de íons positivos (cátions) deve ser aproximadamente igual à concentração de íons negativos (ânions). As amostras se enquadraram no valor limite de erro de $10 \%$, índice recomendado para trabalhos desta natureza.

Para as interpretações hidrogeoquímicas, os dados foram analisados com a aplicação dos métodos gráficos de Piper (1944) e de Stiff (1951). 


\section{4 - RESULTADOS E ANÁLISE ESTATÍSTICA}

A rede de amostragem composta de 46 amostras de águas subterrâneas é apresentada na Figura 3.

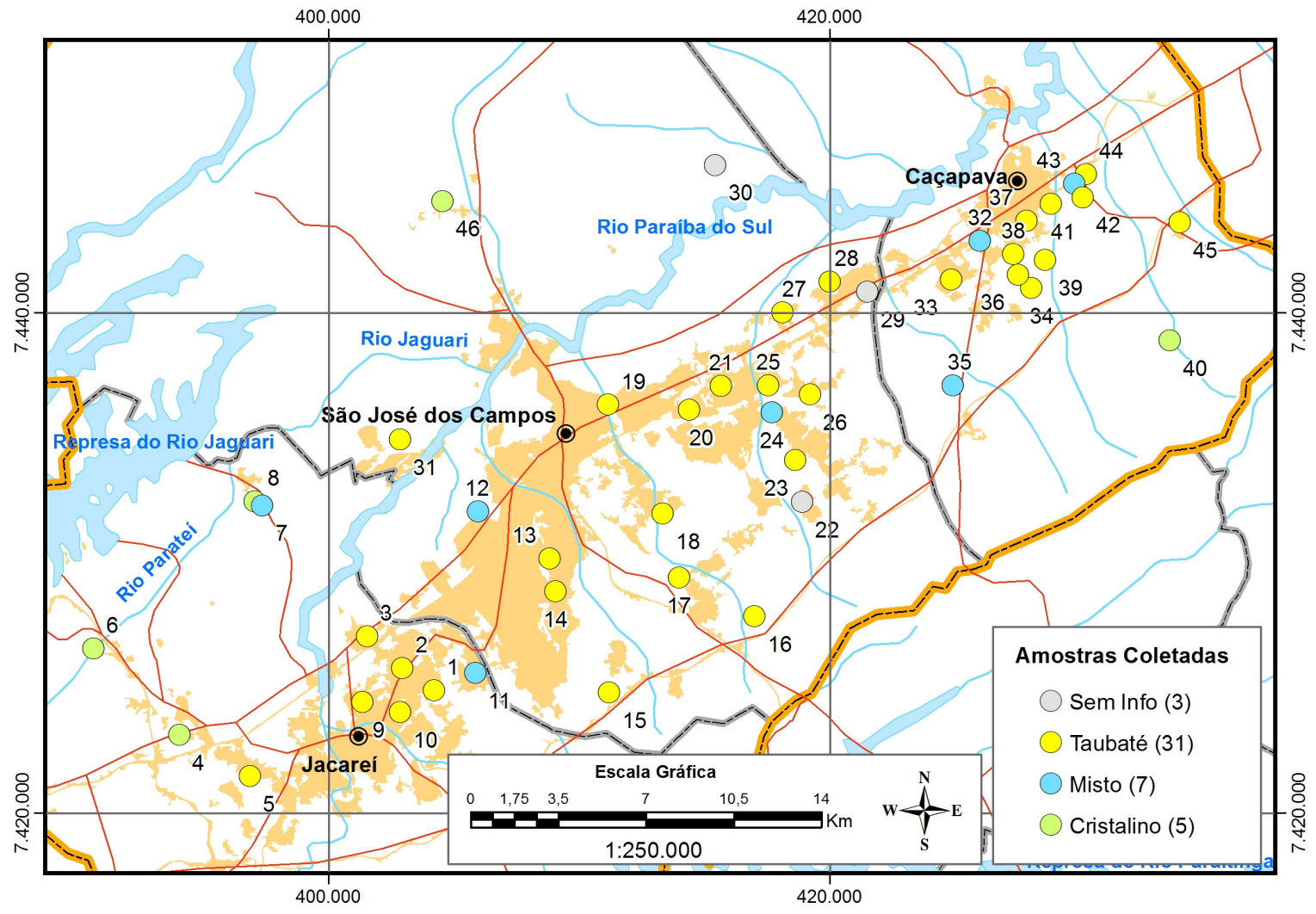

Figura 3. Distribuição espacial da rede de amostragem.

Foi realizada uma análise estatística dos resultados dos principais cátions e ânions, $\mathrm{pH}$ e condutividade elétrica com o objetivo de identificar principais as características hidroquímicas do SAT e do aquífero Cristalino, apresentada nas Tabelas 3 e 4.

Comparando os dados do SAT, Tabela 3, e do aquífero Cristalino, Tabela 4, nota-se que a mediana dos principais íons maiores: sódio, cálcio, magnésio, bicarbonato, sulfato e cloreto são de duas a três vezes mais altas no aquífero Cristalino. Apenas o potássio tem a mediana maior no SAT do que no aquífero Cristalino.

A análise estatística básica dos parâmetros hidroquímicos do SAT pode ser visualizada em detalhe na Tabela 3, no gráfico de estatística básica, Figura 4, e nos histogramas de frequência, Figura 5. Das 46 amostras, considerando-se apenas as amostras representativas do SAT, foram analisadas 31 amostras. 
Tabela 3 - Estatísticas dos parâmetros hidroquímicos do SAT

\begin{tabular}{|c|c|c|c|c|c|c|c|c|c|c|c|c|c|c|c|c|}
\hline & pH & $\mathbf{C E}$ & prof. & HCO3- & F- & Cl- & NO2- & NO3- & PO4-- & SO4-- & $\mathrm{Na}+$ & NH4+ & $\mathbf{K}+$ & $\mathrm{Mg}++$ & $\mathrm{Ca}++$ & $\mathbf{S i}$ \\
\hline Unidade & & $\mu \mathrm{S} / \mathrm{cm}$ & $\mathrm{m}$ & $\mathrm{mg} / \mathrm{L}$ & $\mathrm{mg} / \mathrm{L}$ & $\mathrm{mg} / \mathrm{L}$ & $\mathrm{mg} / \mathrm{L}$ & $\mathrm{mg} / \mathrm{L}$ & $\mathrm{mg} / \mathrm{L}$ & $\mathrm{mg} / \mathrm{L}$ & $\mathrm{mg} / \mathrm{L}$ & $\mathrm{mg} / \mathrm{L}$ & $\mathrm{mg} / \mathrm{L}$ & $\mathrm{mg} / \mathrm{L}$ & $\mathrm{mg} / \mathrm{L}$ & $\mathrm{mg} / \mathrm{L}$ \\
\hline Mínimo & 5,3 & 26 & 81,00 & 0,00 & 0,02 & 0,27 & 0,01 & 0,02 & 0,01 & 0,05 & 0,73 & 0,02 & 1,16 & 0,05 & 0,24 & 12,50 \\
\hline Máximo & 10,4 & 410 & 277,00 & 145,00 & 3,74 & 83,40 & 0,21 & 40,00 & 2,45 & 14,60 & 57,30 & 0,42 & 8,49 & 2,55 & 39,20 & 30,00 \\
\hline Média & 7,3 & 131 & 184,22 & 56,24 & 0,22 & 4,94 & 0,02 & 3,29 & 0,39 & 2,11 & 13,45 & 0,08 & 4,47 & 0,82 & 9,79 & 15,03 \\
\hline Mediana & 7,2 & 97 & 193,60 & 44,30 & 0,08 & 0,96 & 0,01 & 1,11 & 0,21 & 0,52 & 8,83 & 0,03 & 3,94 & 0,68 & 5,35 & 14,00 \\
\hline Desvio padrão & 1,1 & 93,9 & 51,0 & 48,4 & 0,7 & 15,0 & 0,0 & 7,4 & 0,5 & 3,1 & 13,2 & 0,1 & 1,7 & 0,6 & 10,4 & 6,4 \\
\hline Variação & 15 & 72 & 28 & 86 & 300 & 303 & 191 & 226 & 134 & 149 & 98 & 139 & 39 & 78 & 106 & 43 \\
\hline Contagem & 31 & 31 & 30 & 31 & 31 & 31 & 31 & 31 & 31 & 31 & 31 & 31 & 31 & 31 & 31 & 31 \\
\hline
\end{tabular}

Tabela 4 - Estatísticas dos parâmetros hidroquímicos do aquífero Cristalino

\begin{tabular}{|c|c|c|c|c|c|c|c|c|c|c|c|c|c|c|c|c|}
\hline & pH & $\mathbf{C E}$ & prof. & HCO3- & F- & Cl- & NO2- & NO3- & PO4-- & SO4-- & $\mathrm{Na}+$ & NH4+ & $\mathbf{K}+$ & $\mathrm{Mg}++$ & $\mathrm{Ca}++$ & $\mathbf{S i}$ \\
\hline Unidade & & $\mu \mathrm{S} / \mathrm{cm}$ & $\mathrm{m}$ & $\mathrm{mg} / \mathrm{L}$ & $\mathrm{mg} / \mathrm{L}$ & $\mathrm{mg} / \mathrm{L}$ & $\mathrm{mg} / \mathrm{L}$ & $\mathrm{mg} / \mathrm{L}$ & $\mathrm{mg} / \mathrm{L}$ & $\mathrm{mg} / \mathrm{L}$ & $\mathrm{mg} / \mathrm{L}$ & $\mathrm{mg} / \mathrm{L}$ & $\mathrm{mg} / \mathrm{L}$ & $\mathrm{mg} / \mathrm{L}$ & $\mathrm{mg} / \mathrm{L}$ & $\mathrm{mg} / \mathrm{L}$ \\
\hline Mínimo & 5,7 & 146 & 130,00 & 76,00 & 0,06 & 0,56 & 0,01 & 0,02 & 0,02 & 1,75 & 17,30 & 0,03 & 1,71 & 0,53 & 9,52 & 12,50 \\
\hline Máximo & 10,5 & 341 & 204,00 & 197,00 & 0,90 & 5,34 & 0,01 & 2,56 & 0,55 & 15,80 & 40,30 & 0,03 & 4,24 & 8,07 & 37,40 & 25,40 \\
\hline Média & 7,4 & 242 & 173,50 & 136,68 & 0,39 & 2,55 & 0,01 & 0,77 & 0,16 & 5,70 & 27,56 & 0,03 & 2,83 & 3,46 & 20,24 & 18,80 \\
\hline Mediana & 6,8 & 253 & 180,00 & 143,00 & 0,29 & 2,18 & 0,01 & 0,02 & 0,07 & 2,36 & 23,60 & 0,03 & 2,46 & 2,46 & 16,30 & 17,50 \\
\hline Desvio padrão & 1,8 & 93,4 & 35,2 & 56,2 & 0,3 & 1,8 & 0,0 & 1,1 & 0,2 & 5,9 & 10,0 & 0,0 & 1,1 & 3,1 & 12,0 & 4,1 \\
\hline Variação & 24,6 & 38,6 & 20,3 & 41,1 & 81,8 & 69,3 & 0,0 & 146,9 & 139,6 & 104,0 & 36,1 & 0,0 & 39,4 & 88,9 & 59,4 & 21,7 \\
\hline Contagem & 5 & 5 & 4 & 5 & 5 & 5 & 5 & 5 & 5 & 5 & 5 & 5 & 5 & 5 & 5 & 5 \\
\hline
\end{tabular}


Conforme pode ser observado no gráfico de estatística básica, Figura 4, os principais cátions e ânions que caracterizam a qualidade da água subterrânea no SAT são o sódio, o cálcio e o bicarbonato.

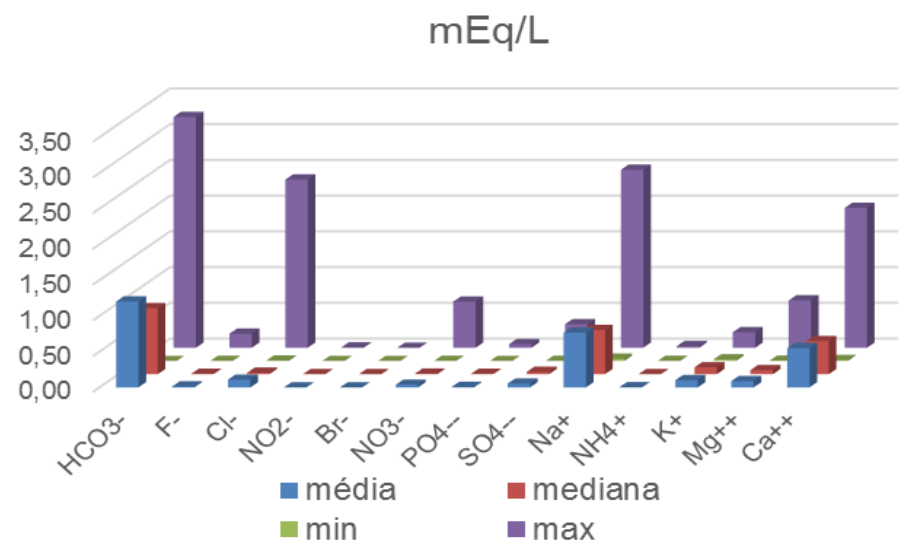

Figura 4 - Gráfico de estatística básica das amostras do SAT (mEq/L)

Os valores de $\mathrm{pH}$ mostram que as águas do SAT são tipicamente neutras. A condutividade elétrica (C.E.) das amostras coletadas no SAT possuem condutividade elétrica menor do que 100 $\mu \mathrm{S} / \mathrm{cm}$, indicando águas tipicamente de baixa salinidade. O principal ânion detectado foi o bicarbonato e análise do histograma de frequência mostra uma importante configuração, com a menor porcentagem e amostras ocorrendo na região central do histograma, denotando uma tipificação distinta de águas, quanto às concentrações de bicarbonato, dentro do próprio SAT.

$\mathrm{O}$ nitrato $\left(\mathrm{NO}_{3}{ }^{-}\right)$apresenta elevada dispersão nos valores, com coeficiente de variação da ordem de 226\%, caracterizando ocorrências anômalas de concentrações. Os teores de nitrato verificados nas águas subterrâneas do SAT foram de 0,02 mg/L a 40,00 mg/L, com uma média de 3,29 mg/L e mediana de 1,11 mg/L. A amplitude entre a média e mediana, demonstra que há poucos valores anômalos elevando a média dos resultados. A mediana pode ser representativa do padrão natural de qualidade das águas do SAT para o nitrato. Destaca-se que embora todos os valores estejam dentro dos padrões de potabilidade estabelecidos pela legislação brasileira e pela Organização Mundial de Saúde (45 mg/L de $\mathrm{NO}_{3}{ }^{-}$, equivalente a $10 \mathrm{mg} / \mathrm{L}$ de $\mathrm{N}^{-\mathrm{NO}_{3}}{ }^{-}$), a concentração máxima detectada: $40 \mathrm{mg} / \mathrm{L}$, está próxima ao limite para potabilidade. Pode-se considerar que concentrações de $\mathrm{NO}_{3}{ }^{-}$no $\mathrm{SAT}$, acima de $5 \mathrm{mg} / \mathrm{L}$ sejam decorrentes de alterações de qualidade por interferência antrópica, observado que o padrão natural está em torno de $1 \mathrm{mg} / \mathrm{L}$.

Do universo de 46 amostras realizadas neste trabalho, 05 amostras foram representativas do aquífero Cristalino. Em comparação com o SAT a mediana dos principais íons maiores: sódio, cálcio, magnésio, bicarbonato, sulfato e cloreto são de duas a três vezes mais altas no aquífero Cristalino. Apenas o potássio tem a mediana menor no aquífero Cristalino do que no SAT. 

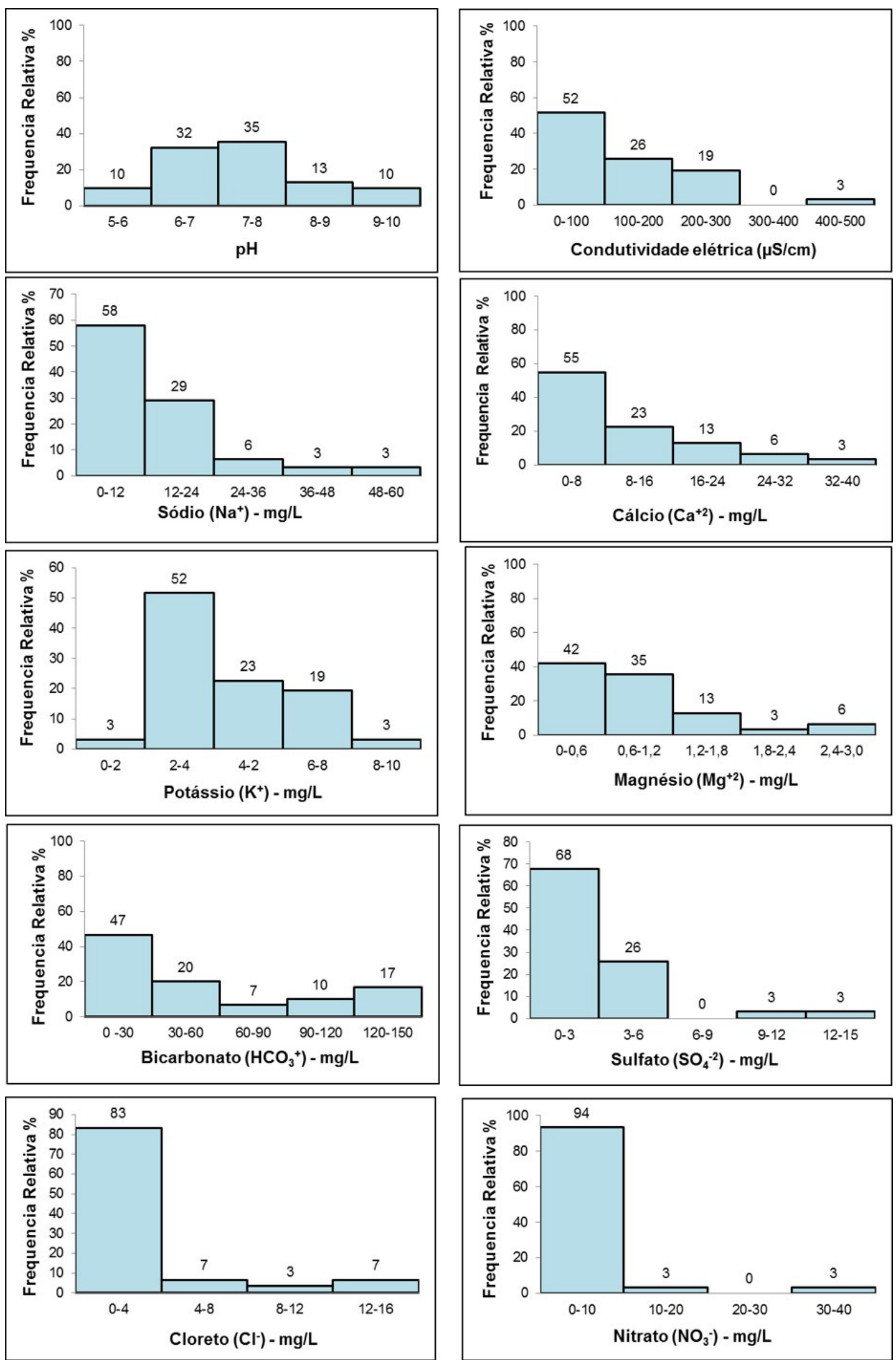

Figura 5. Histogramas de frequência dos parâmetros de qualidade da água subterrânea do SAT 
Desconsiderando-se as amostras de águas impactadas por interferências de origem antrópica, com altas concentrações de nitrato e cloreto, o maior valor de condutividade elétrica foi de 341 $\mu \mathrm{S} / \mathrm{cm}$, observada numa amostra do aquífero Cristalino (C3-46) do poço SJ-297.

No aquífero Cristalino, assim como no SAT, os principais íons na composição química da água são o sódio, o cálcio e o bicarbonato. A principal diferença observada pela análise estatística das amostras dos poços no aquífero Cristalino e no SAT é que no aquífero Cristalino os menores valores de concentração são significativamente mais altos do que no SAT. A condutividade elétrica (C.E.) no aquífero Cristalino mostrou valores numa faixa maior da maioria das amostras do SAT. O pH no aquífero Cristalino, assim como no SAT, também foi neutro. O nitrato $\left(\mathrm{NO}_{3}{ }^{-}\right)$foi detectado de $0,02 \mathrm{mg} / \mathrm{L}$ a 2,56 mg/L, não apresentando, portanto, alterações significativas de qualidade da água nos poços coletados no aquífero Cristalino.

A condutividade elétrica (CE) das águas do SAT e do Cristalino variou de $17 \mu \mathrm{S} / \mathrm{cm}$ a 410 $\mu \mathrm{S} / \mathrm{cm}$, com média e mediana, respectivamente, de $131 \mu \mathrm{S} / \mathrm{cm}$ e $97 \mu \mathrm{S} / \mathrm{cm}$. O valor de $410 \mu \mathrm{S} / \mathrm{cm}$ foi uma anomalia provocada pela presença de cloreto na amostra C3-33, relativa ao poço CA-188.

\section{5 - ANÁLISE HIDROGEOQUÍMICA}

As variações hidroquímicas podem ocorrer naturalmente em função da dinâmica da solução, dos padrões de fluxo e da litologia, bem como por interferência antrópica. A qualidade das águas determinadas por análises químicas pode ser avaliada graficamente por métodos de classificação, analíticos ou de correlação (Zaporozec, 1972). As comparações de qualidade das águas considerando a proporcionalidade dos íons na constituição das amostras analisadas, depende de avaliações com os teores miliequivalentes dos constituintes e, para tanto, foram aplicados os métodos gráficos de Piper (1944) e de Stiff (1951). A interpretação com a utilização dos diagramas de Piper e de Stiff possibilita a diferenciação entre tipos hidroquímicos, permitindo a classificação das águas, bem como a variação espacial dos tipos hidroquímicos.

Vidal (1997) utilizou a análise multivariada de agrupamento para a determinação dos tipos hidroquímicos do SAT e identificou quatro tipos hidroquímicos. Considerando a área de estudo do presente trabalho, ocorrem na área o tipo I e o tipo II, descritos por Vidal (1997). Conforme Vidal (1997), o Tipo I é caracterizado por apresentar salinidade de 28 e 207 mg/l, com a maior parte das águas classificadas como bicarbonatadas sódicas, porém, com varirações para bicarbonatadas cálcicas e cloro-sulfatadas sódicas. E o Tipo II é caracterizado por águas bicarbonatadas cálcicas e sódicas, com salinidades de 165 a 350mg/L. 
Numa abordagem gráfica, Vidal (1997) elaborou diagramas de Piper juntamente com os resultados obtidos nos histogramas de salinidade e observou que, com o aumento da salinidade, há um aumento na participação dos ânions carbonato e bicarbonato e dos cátions sódio e potássio. Observou que as águas do SAT, em relação aos valores de C.E., indica teores predominante de baixa salinidade. Conforme caracterizado por Vidal (1997), Vidal \& Chang (2002) e Vidal \& Chang (2004) os valores de sólidos totais dissolvidos - STD variam de 28 a 207 mg/L no Compartimento Jacareí-São José dos Campos (Tipo I) e de 165 a 350mg/L na região do Alto de Caçapava (Tipo II).

\section{1 - Refinamento de dados para a caracterização e classificação hidrogeoquímica}

A análise geral das amostras pode ser visualizada na Figura 6, que apresenta o diagrama de Piper para todo o universo amostral adotado nesta avaliação hidrogeoquímica. Foi possível observar que as águas do aquífero Cristalino, bem como de poços Mistos - aquífero Cristalino e SAT concentram-se na área atribuída ao Tipo II de Vidal (1997), juntamente com determinadas águas do aquífero Taubaté.

Optou-se por trabalhar em maior detalhe sobre os dados definidos como sendo do SAT ou do aquífero Cristalino, visando o reconhecimento de variações sensíveis nas águas do próprio SAT, bem como suas relações com as águas do aquífero Cristalino.

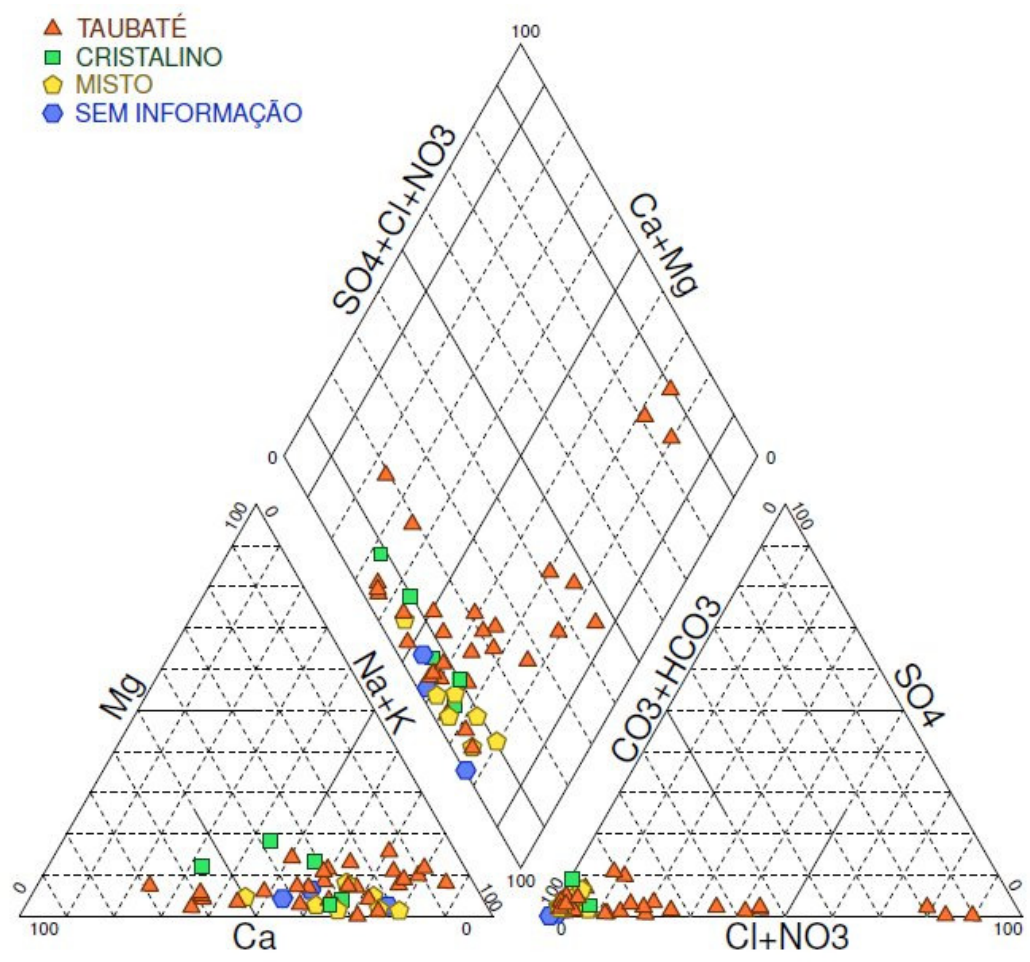

Figura 6. Diagrama de Piper com dados identificadas pelo sistema aquífero 
Uma vez conhecidas algumas anomalias de concentração relativas a interferências de origem antrópica sobre a qualidade natural das águas e sabendo-se que a ocorrência de nitrato é bastante característica na representatividade dessas interferências, foi elaborado um diagrama de Piper, Figura 7, identificando as diferentes concentrações de nitrato, de modo a permitir que amostras com resultados anômalos pudessem ser visualizadas e, posteriormente, desconsideradas na avaliação das características hidroquímicas naturais da água.

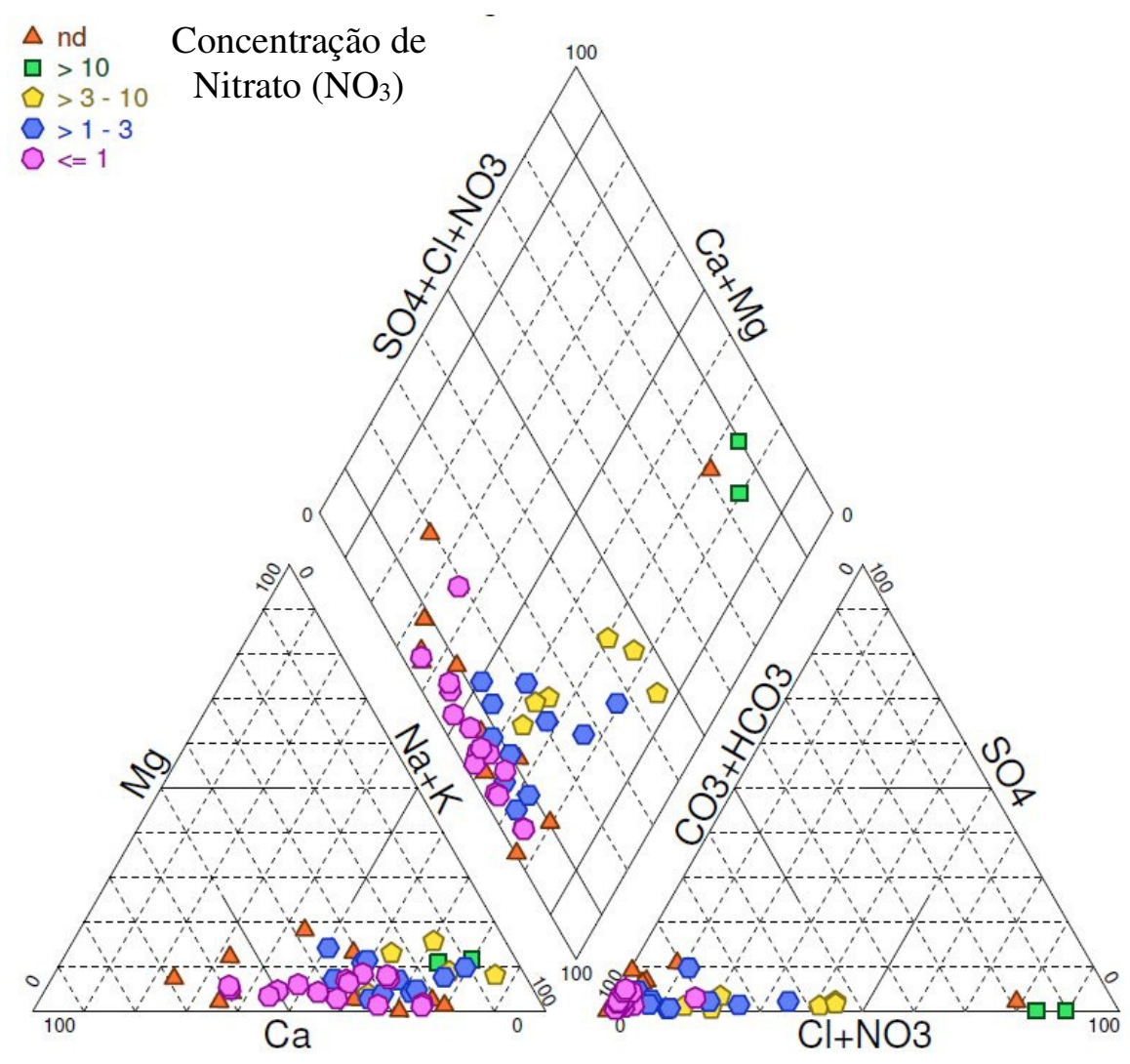

Figura 7. Diagrama de Piper com identificação das variações de concentração de Nitrato

\section{2 - Caracterização hidrogeoquímica}

Com esta seleção de dados, foram elaborados diagramas de Stiff, Figura 8, que associados ao diagrama de Piper, Figura 9, e a uma observação detalhada da distribuição espacial de concentrações dos parâmetros de interesse (apresentada nos tópicos seguintes) permitiram caracterizar sensíveis diferenciações entre águas do próprio SAT e suas relações com as águas do aquífero Cristalino. 
Desse modo, foi possível separar quatro zonas características na avaliação hidrogeoquímica, descritas da seguinte maneira:

- Taubaté1 - Salinidade intermediária e baixas concentrações de Cálcio, localizada na região central da área de estudos e limitada aos municípios de Jacareí e São José dos Campos.

- Taubaté2 - Salinidade muito baixa e razão iônica K / Na positiva, localizada nas regiões norte, oeste e sul, ao longo de depósitos quaternários e limitada aos municípios de Jacareí e São José dos Campos.

- Taubaté3 - Salinidade e concentrações de Cálcio relativamente altas, similares às águas do Cristalino, localizada na região leste da área de estudos e limitada ao município de Caçapava e extremo leste de São José dos Campos, próximo ao Alto de Caçapava;

- Cristalino - Salinidade e concentrações de Cálcio mais altas, localizada nas porções Noroeste e Sudeste da área de estudos, nos três municípios.

Comparando aos resultados de Vidal (1997), pode-se atribuir que as zonas aqui definidas como Taubaté1 e Taubaté2 correspondem ao Tipo I de Vidal (1997) e as zonas Taubaté3 e Cristalino ao Tipo II de Vidal (1997).

Considerando os tipos de água discriminados na área de estudo, pôde-se verificar as seguintes faixas aproximadas de variação de condutividade elétrica:

- Taubaté1 - $50 \mu \mathrm{S} / \mathrm{cm}$ a $150 \mu \mathrm{S} / \mathrm{cm}$

- Taubaté2 - até $50 \mu \mathrm{S} / \mathrm{cm}$

- Taubaté3 - $100 \mu \mathrm{S} / \mathrm{cm}$ a $250 \mu \mathrm{S} / \mathrm{cm}$

- Cristalino - $150 \mu \mathrm{S} / \mathrm{cm}$ a $350 \mu \mathrm{S} / \mathrm{cm}$

A Figura 10 mostra a localização e distribuição das amostras coletadas com a identificação do aquífero Cristalino e variações no SAT. 


\section{taubaté1}

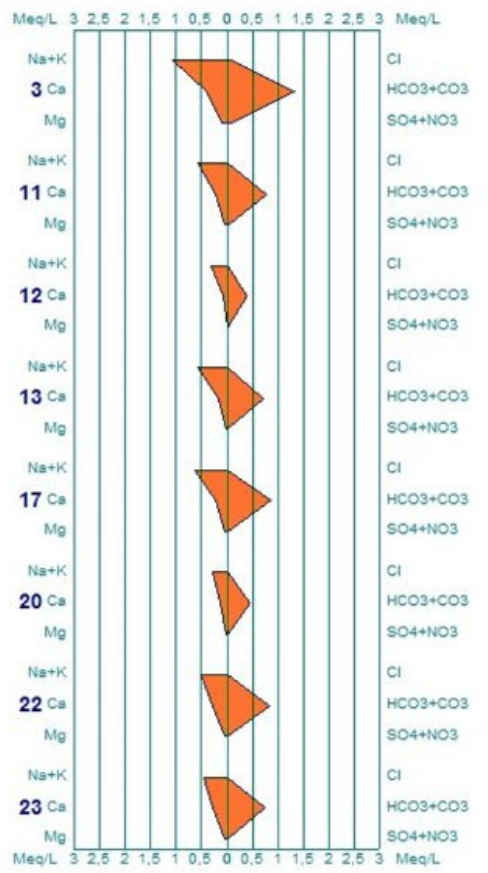

taubaté2

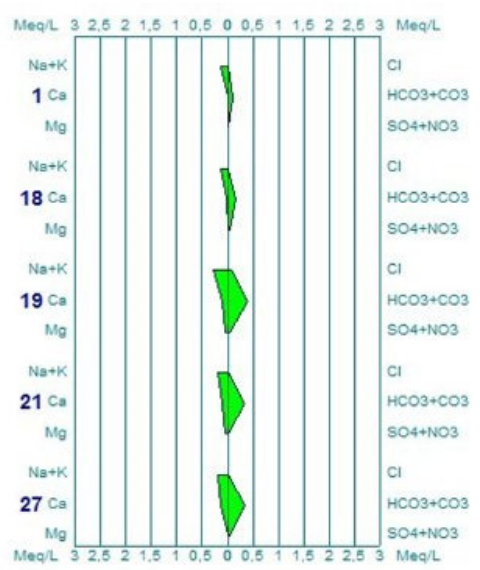

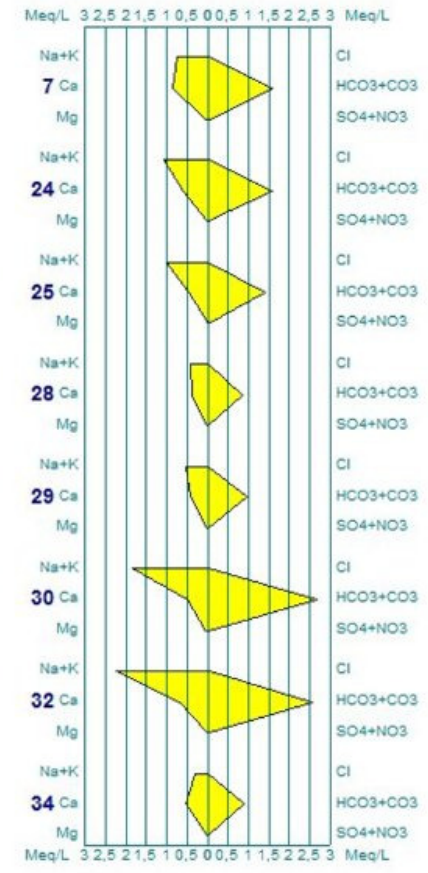

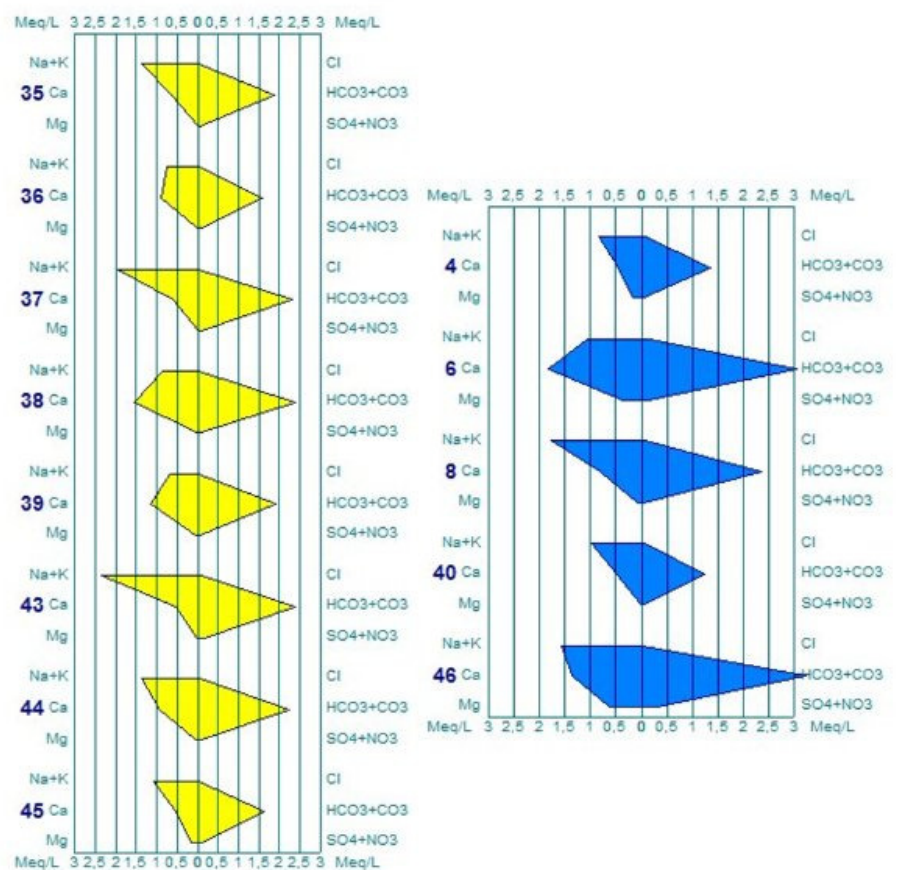

Figura 8. Diagramas de Stiff com identificação do aquífero Cristalino e das diferenciações identificadas no SAT 


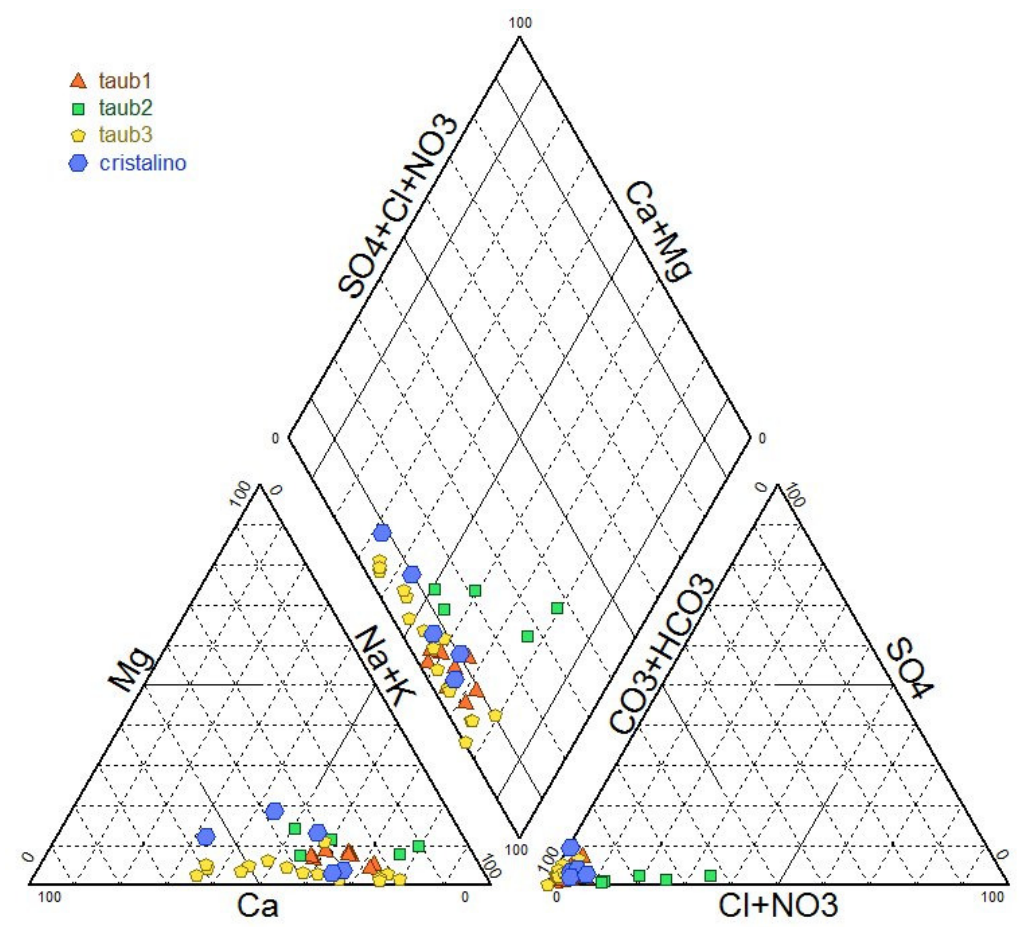

Figura 9. Diagrama de Piper com identificação do aquífero Cristalino e variações no SAT.

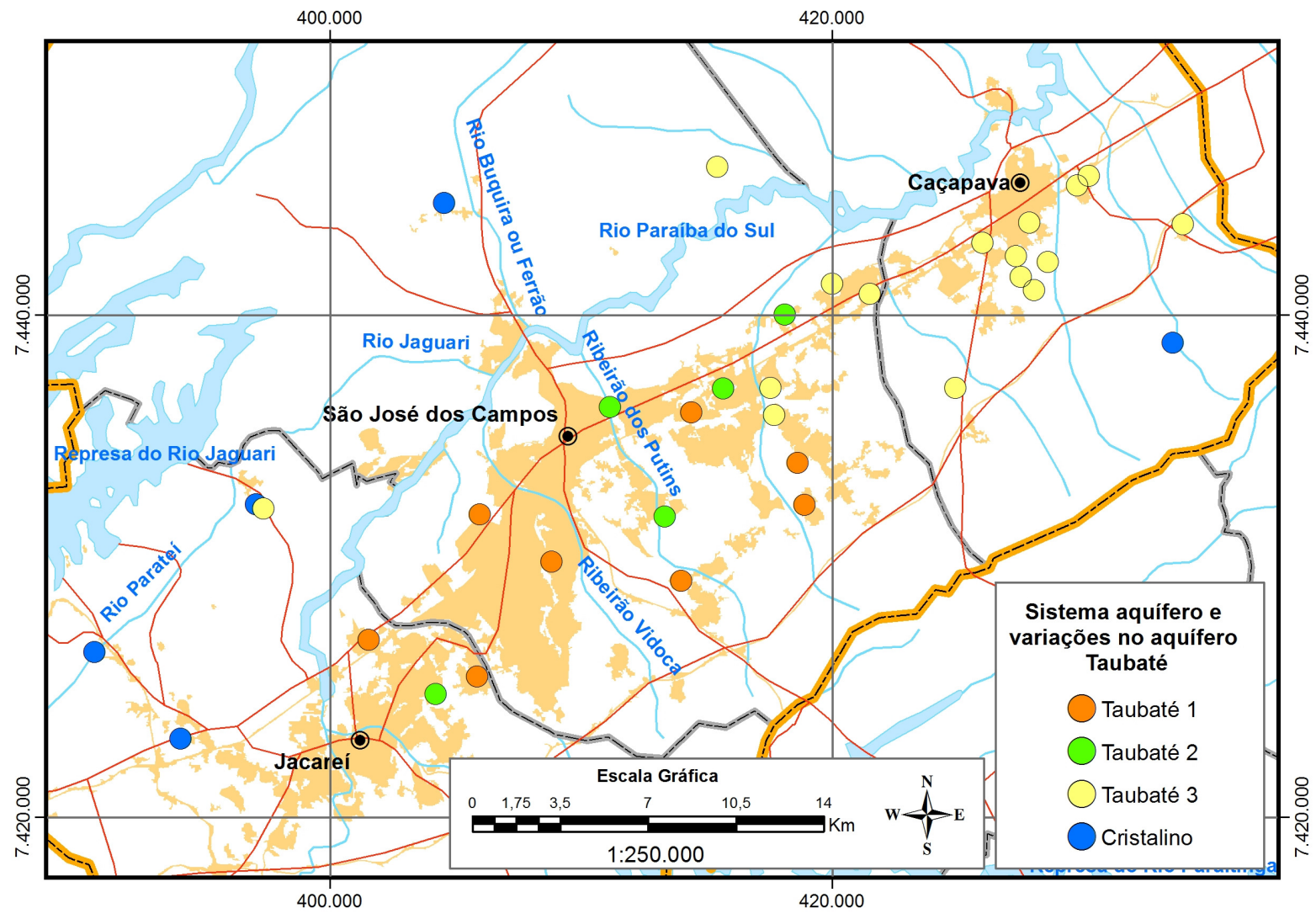

Figura 10. Distribuição das amostras coletadas com a identificação do aquífero Cristalino e variações no SAT 


\section{3 - Classificação hidrogeoquímica}

A Figura 11 apresenta a classificação hidroquímica para cada uma das zonas de água definidas:

- Taubaté1 - Bicarbonatadas sódicas;

- Taubaté2 - Bicarbonatadas potássicas;

- Taubaté3 - Bicarbonatadas sódicas a Bicarbonatadas cálcicas;

- Cristalino - Bicarbonatadas sódicas a Bicarbonatadas cálcicas.

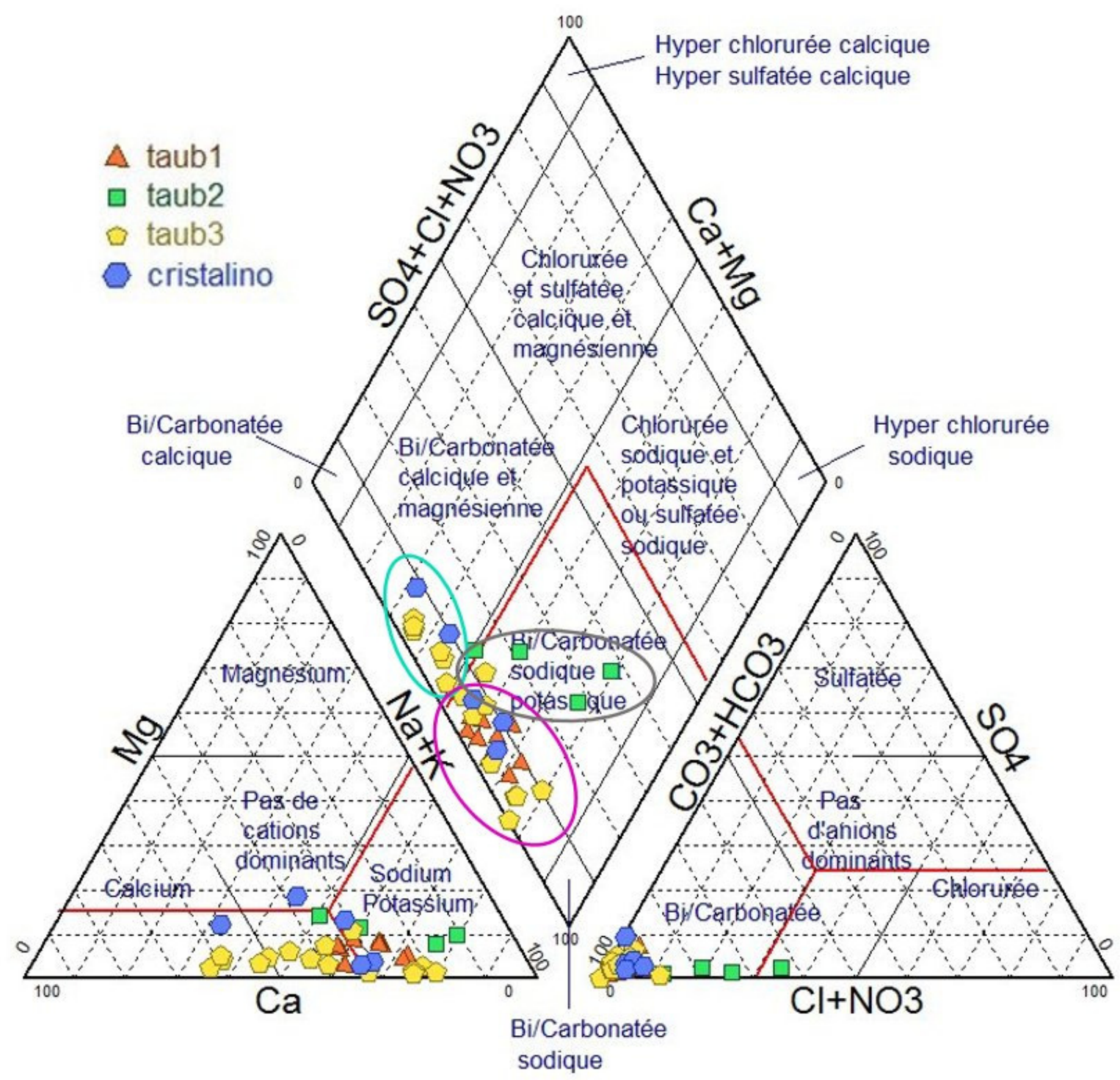

Figura 11. Diagrama de Piper dos dados analíticos realizados e classificação de águas 


\section{6 - DISCUSSÃO DE RESULTADOS}

O fato de se trabalhar com amostras coletadas num período específico e sob as mesmas metodologias de coleta e análise; associado ao refinamento dos dados com a exclusão de amostras com concentrações anômalas de contaminantes ou aquelas provindas de aquíferos indeterminados; permitiu diminuir incertezas, dando segurança para se considerar pequenas variações da qualidade da água. Assim foi possível diferenciar águas dentro do próprio SAT, bem como reconhecer correlações das águas do SAT com as águas do aquífero Cristalino. Permitindo, portanto, o agrupamento de diferentes tipos hidroquímicos, mesmo sob variações sutis das características naturais das águas.

A semelhança das águas do tipo Taubaté3 com as águas do aquífero Cristalino, provavelmente está associada a uma contribuição do aquífero Cristalino para o SAT, o que é indicado pela proximidade de águas do tipo Taubaté3 ao Alto Estrutural de Caçapava, na porção leste da área de estudos. Já em relação Às águas do tipo Taubaté2, em contraponto a esta observação, ou seja, à contribuição do aquífero Cristalino para o SAT, os valores de STD muito baixos observados no tipo Taubaté 2 -na porção central da área de estudos - indicam a ocorrência de uma recarga local direta no SAT. Estes dois fatores denotam a complexidade da dinâmica de fluxo das águas subterrâneas nessa região.

A maior concentração de nitrato detectada: $40 \mathrm{mg} / \mathrm{L} \mathrm{NO}_{3}{ }^{-}$, ou $9 \mathrm{mg} / \mathrm{L}$ seguindo a notação $\mathrm{N}$ $\mathrm{NO}_{3}$; embora abaixo, está próxima ao limite de referência - de $45 \mathrm{mg} / \mathrm{L} \mathrm{NO}_{3}{ }^{-}$, pela Organização Mundial de Saúde ou o equivalente: $10 \mathrm{mg} / \mathrm{L}$ de N-NO3, pela Portaria 2914/2011 do Ministério da

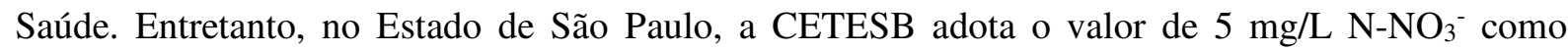
referência, e a partir desse valor recomenda a tomada de ações de prevenção e controle, por suspeita de influência antrópica na qualidade da água subterrânea (Rosenberger, 2013).

De acordo com Foster et. al. (2006), em escala mundial, os aquíferos estão sob uma crescente ameaça de contaminação causada pela urbanização, desenvolvimento industrial, atividades agrícolas e mineração. Em áreas urbanizadas, como na área de estudo - a porção oeste do Vale do Paraíba - a maior preocupação é a carga contaminante relativa ao sistema de saneamento, com destaque às fossas sépticas e negras, à fuga das redes coletoras de esgoto e ao descarte de esgotos não tratados. 


\section{7 - CONCLUSÕES}

Neste trabalho foram caracterizadas e classificadas quatro zonas hidroquímicas: Taubaté1, Bicarbonatadas sódicas; Taubaté2, Bicarbonatadas potássicas; Taubaté3, Bicarbonatadas sódicas a Bicarbonatadas cálcicas; e Cristalino, Bicarbonatadas sódicas a Bicarbonatadas cálcicas.

Esta caracterização permitiu observar uma interação de águas do aquífero fraturado Cristalino com águas dos aquíferos granulares do Sistema Aquífero Taubaté, denotada pela forte semelhança entre as águas do Cristalino e as águas do tipo Taubaté3, no SAT.

A predominância de águas do tipo Taubaté3 nas proximidades do Alto Estrutural de Caçapava é indicativa de uma contribuição do aquífero Cristalino para o SAT nesta localidade. Enquanto, por outro lado, os baixos valores de STD observados no tipo Taubaté2 são indicativos de uma zona de recarga local direta no SAT.

Foram verificadas ocorrências anômalas de nitrato e cloreto nas águas, decorrentes de interferência antrópica, que embora tenham sido pontuais e abaixo dos limites de referência aplicáveis, alertam para a necessidade de melhorias na gestão dos aquíferos. Estas medidas incluem desde um melhor planejamento do uso e ocupação do solo, que leve em conta as potencialidades e vulnerabilidades dos aquíferos; passando por ações de saneamento mais efetivas na coleta e tratamento de esgoto; até o melhor conhecimento da totalidade da rede de poços existentes, que propicie uma gestão específica do uso da das águas subterrâneas.

\section{8 - BIBLIOGRAFIA}

CARVAlhO, A. M. A; VIDAL, A. C.; CHANG, H. K. 2011. Delimitação do Embasamento da Bacia de Taubaté. REVISTA SÉRIE CIENTÍFICA, GEOLOGIA, USP. Instituto de Geociências / USP, São Paulo, v. 11, n. 1, p. 19-32, 2011.

CETESB. Companhia Ambiental do Estado de São Paulo. Relação de Áreas Contaminadas e Reabilitadas do Estado de São Paulo - Texto Explicativo. CETESB, São Paulo, 2013, 14 p.

CPRM. Companhia de Pesquisa dos Recursos Minerais. Geodiversidade do estado de São Paulo. Carlos Augusto Brasil Peixoto [org.]. São Paulo: CPRM, 2010. 176 p.+ 1 DVD-ROM.

CUSTÓDIO, E; LLAMAS, M.R. Hidrologia Subterrânea $2^{\text {a }}$ Edicion. Barcelona;Ediciones Omega 1983 ;

DAEE. Departamento de Águas e Energia Elétrica. Estudo de Águas Subterrâneas: região administrativa 7 - Bauru; 8 - São José do Rio Preto; e 9 - Araçatuba. 4 volumes. DAEE / ENCO, São Paulo, 1976. 
FERNANDES, F. L. Arcabouço estrutural e evolução da Bacia de Taubaté - SP. Dissertação (Mestrado) - Universidade Federal de Ouro Preto, Ouro Preto, MG, 147 f., 1993.

FERNANDES, F. L.; CHANG, H. K. Arcabouço estrutural da Bacia de Taubaté - SP. In: SIMPÓSIO NACIONAL DE ESTUDOS TECTÔNICOS, 9, 2003, Búzios. Boletim de Resumos... Búzios: SBG-Núcleos Rio de Janeiro/ Espírito Santo, 2003. p. 367-370.

FOSTER, S. S. D.; HIRATA. R. C. A.; GOMES, D. C.; D’ELIA, M.; PARIS, M. Proteção da qualidade da água subterrânea: um guia para empresas de abastecimento de água, órgãos municipais e agências ambientais. Banco Mundial / Servmar. São Paulo, 2006.

IBGE. Instituto Brasileiro de Geografia e Estatística. Censo 2010: Características da população por município. Rio de Janeiro, 2010a.

IRITANI, M. A. 1999. Mapeamento da vulnerabilidade e risco de poluição das águas subterrâneas no Estado de São Paulo - detalhamento da Região Metropolitana de Campinas (RMC). $2^{\mathrm{a}}$ Reunião sobre Pesquisa Ambiental na SMA, São Paulo. Boletim de Resumos... Secretaria do Meio Ambiente, São Paulo, 194-198.

MANCINI, F. Estratigrafia e aspectos da tectônica deformadora da Formação Pindamonhangaba, Bacia de Taubaté, SP. 1995. 107 f. Dissertação (Mestrado) - Instituto de Geociências, Universidade de São Paulo, São Paulo, 1995.

PIPER A.M. 1944. A graphic procedure in the geochemical interpretation of water-analyses. Am. Geophys. Union Trans. 25: 914-923.

RICCOMINI, C., 1989. O Rift Continental do Sudeste Brasileiro. São Paulo. 256 p. (Tese de Doutoramento/Instituto de Geociências da USP).

ROSENBERGER, M. Mapeamento da Vulnerabilidade natural à contaminação do Sistema Aquífero Bauru na área urbana do Município de Bauru (SP). Trabalho de Graduação Individual de Bacharelado em Geografia. Departamento de Geografia da Faculdade de Filosofia, Letras e Ciências Humanas da Universidade de São Paulo. São Paulo, 2013. 128 p.

STIFF, H.A. The interpretation of chemical water analysis by means of paterns. Journal of Petroleoum Technology 3(10):15-17. 1951;

VIDAL, A.; FERNANDES, F. L.; CHANG, H. K. Distribuição dos arenitos na Bacia de Taubaté. São Paulo. Geociências UNESP, v.23, n1/2, p. 55-66. 2004.

VIDAL, A.C. \& Chang, H.K. 2004. Análise Geoestatística da Salinidade dos Aquíferos da bacia de Taubaté. Revista Brasileira de Geociências, 34(1):109-116.

VIDAL, A.C. \& Chang, H.K. 2002. Caracterização hidroquímica dos aquíferos da Bacia de Taubaté. Revista Brasileira de Geociências, 32(2):267-276. 
VIDAL, A. C. 1997. Caracterização Hidrogeoquímica dos compartimentos estruturais da Bacia de Taubaté, SP. Campinas. 128p. Dissertação (mestrado) Universidade Estadual de Campinas Instituto de Geociências.

ZAPOROZEC, A. Graphical interpretation of water-quality data: ground water. v 10, n 2. 1972. p. 32-43. 